\title{
Correlation between acute coronary events and body mass index values
}

\section{Corelaţia dintre evenimentele coronariene acute şi valorile indicelul de masă corporală}

\author{
Maria Marilena FRUNZULICĂ ${ }^{1}$, Doina CÂRSTEA ${ }^{1}$, Andreea Lorena ENACHE ${ }^{2}$, \\ Claudia PĂTULARU ${ }^{3}$ \\ ${ }^{1}$ Disciplina Semiologie Medicală, Universitatea de Medicină şi Farmacie Craiova, România \\ ${ }^{2}$ Secția Neurologie, Spitalul Municipal Calafat, România \\ ${ }^{3}$ Cabinet individual medicină de familie, Rm. Vâlcea, România
}

\section{ABSTRACT}

The study analyzed the correlation between body mass index (BMI) values and the occurrence of acute coronary events (ACE) on a sample of 865 subjects. In order to evaluate the ACE risk, the BMI was followed, and according to its values, the classification of subjects into groups of normoponderales, overweight and obese. The prevalence of ACE was increasing in relation to the increase in BMI, being maximum in obese subjects (10\%), and $7.52 \%$ in the overweight ones.

Keywords: acute coronary events (ACE), body mass index (BMI), obesity, normoponderal, overweight

\section{REZUMAT}

Studiul a analizat corelația dintre valorile indicelui de masă corporală (IMC) şi apariția evenimentelor coronariene acute (ECA) pe un eşantion de 865 de subiecți. Pentru evaluarea riscului ECA, s-a urmărit IMC şi, în funcție de valorile acestuia, încadrarea subiecților în grupe de normoponderali, supraponderali și obezi. Prevalența ECA a fost crescătoare în raport cu creşterea IMC, fiind maximă la subiecții obezi (10\%), şi de 7,52\% la cei supraponderali.

Cuvinte cheie: evenimente coronariene acute (ECA), indice de masă corporală (IMC), obezitate, normoponderal, supraponderal

\section{INTRODUCERE}

Termenul de „indice de masă corporală“ a fost conceput de Adolphe Quetelet, un astronom belgian, matematician, statistician și sociolog, care a elaborat conceptul de „fizică socială“ (10). Ancel Benjamin Keys, un fiziolog american care a studiat influența dietei asupra sănătății, a introdus termenul modern de index de masă corporală (IMC), definit ca raportul dintre greutate și înălțimea la pă- trat, într-o lucrare publicată în ediția din iulie 1972 a revistei „Journal of Chronic Diseases“, ca un indicator relativ al obezități $(11,12,13)$.

Originea cuvântului „obezitate" se găsește în latină, „obesidas" fiind un cuvânt derivat de la verbul "ob edo, od edere" = „a mânca mult si lacom, a mânca în exces". Obezitatea este definită ca o stare patologică manifestată printr-o îngrășare anormală (14), este o afecțiune medicală de nutriție și metabolism ce duce la diverse afecțiuni și probleme 
de sănătate, care pot determina o speranță de viață redusă $(15,16,17)$.

Inițial, o afecțiune rar întâlnită, a devenit o problemă serioasă după secolul XX, la început doar în țările dezvoltate, ulterior și în țările în curs de dezvoltare, cel mai frecventă urban, iar rata obezității în creștere la nivel mondial a determinat OMS să o recunoască oficial, în anul 1997, drept o epidemie globală $(19,20,21,22)$.

Creșterea indicelui de masă corporală (IMC) mărește riscul de apariție a bolii cardiovasculare $(1,2,3)$, iar valorile ridicate ale tensiunii arteriale, colesterolului și glicemiei modifică parțial efectele. Încercările de a modifica obiceiurile culinare din prezent pentru controlarea greutății sunt utile doar pe termen scurt $(4,5)$, majoritatea medicamentelor pentru scădre ponderală neavând eficiență constantă și persistentă și nici profil acceptabil de siguranță $(6,7)$. Intervenția chirurgicală este indicată doar persoanelor cu grad ridicat al IMC $(8,9)$.

Au fost efectuate cercetări multiple ca urmare a frecvenței în creștere la nivel mondial a bolilor cardiovasculare datorate creșterii IMC și a prevalenței persoanelor supraponderale și obeze în tot mai multe țări de pe glob $(8,9)$.

Această situație a generat preocupări cu privire la o creștere potențială masivă la nivel mondial a bolilor cardiovasculare ca fiind rezultat al creșterii IMC și al prevalenței excesului de greutate și al obezității în majoritatea țărilor (18).

În ultimii ani, numărul persoanelor supraponderale și obeze a crescut foarte mult, la nord-americani prevalența crescând de la 40-43\% în anii '80 la aproape $70 \%$ în prezent, atât la bărbați, cât și la femei.

Creșterea alarmantă a numărului persoanelor obeze și supraponderale s-a înregistrat și în Australia, Sudul Africii, America Centrală și de Sud. În
Europa de Est, prevalența persoanelor supraponderale este de 40-50\%, însă, în ultimele decenii, creșterea s-a mai atenuat (18).

Studiile au arătat ca valori ridicate ale IMC determină un risc de mortalitate prin boli cardiovasculare de $30 \%$ la fiecare $5 \mathrm{~kg} / \mathrm{mp}$ în plus peste 22,5-25 kg/mp. La $30-35 \mathrm{~kg} / \mathrm{mp}$, supraviețuirea mediană scade cu 2-4 ani; la 40-45 kg/mp, scade cu 8-10 ani (ceea ce este asemănător comparativ cu efectele fumatului) (1).

\section{SCOPUL STUDIULUI}

Studiul a urmărit corelația dintre creșterea indicelui de masă corporală și prevalența evenimentelor coronariene acute.

\section{MATERIAL ŞI METODĂ}

Lotul, dimensionat la un număr de 865 de subiecți, a fost realizat prin selectarea randomizată a unui număr de subiecți de sex masculin și feminin, cu profil asemănător cu cel al populației generale.

Valoarea medie a IMC la subiecții afectați de ECA $(24,69)$ nu a variat elocvent comparativ cu valoarea medie a IMC a subiecților fără $\operatorname{ECA~}(25,76)$. Valoarea medie a indicelui de masă corporală la subiecții de gen masculin a fost 25,90 la cei fără ECA și 26,64 la cei cu ECA, iar la cei de gen feminin - 23,718 la cei fără ECA și 25,21 la cei cu ECA.

Prevalența ECA la subiecții cu IMC peste 25 (supraponderali și obezi) a fost aproximativ dubla valorilor indicelui de masă corporală mai mari de 25 , aceasta a fost dublă $(8,11 \%)$ în comparație cu prevalența ECA la subiecți normoponderali, cu un indice de masă corporală sub 25 (4,07\%).

Prevalența ECA la subiecții obezi (cu IMC > 30) a fost $10 \%$, și de $7,52 \%$ la subiecții supraponderali.

Fără ECA $\square$ Cu ECA

26.64

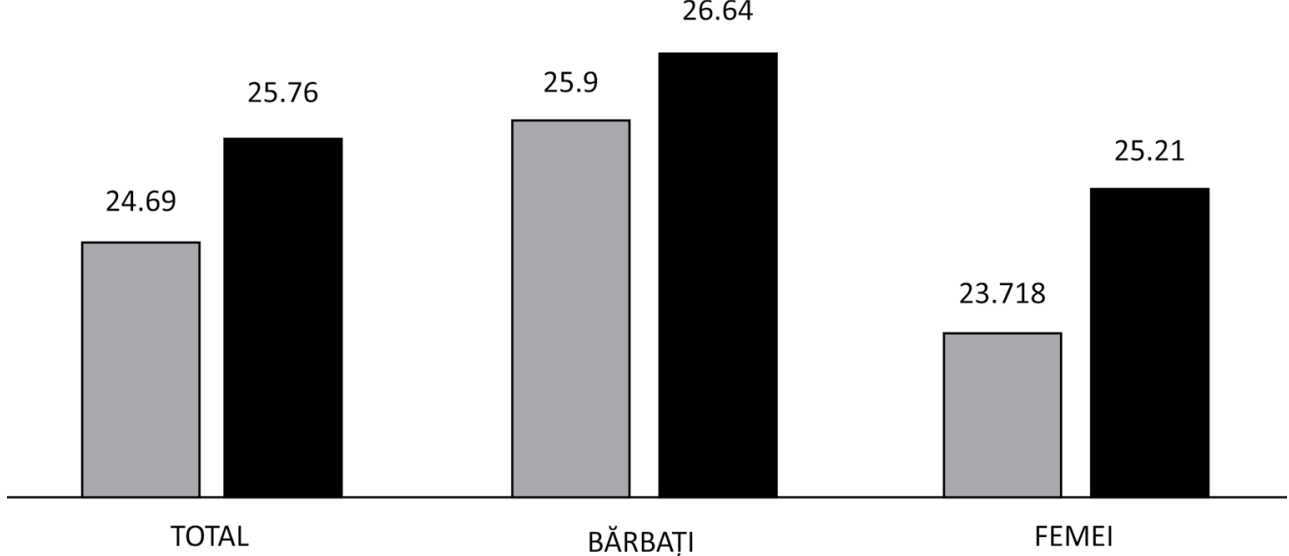

TOTAL
BĂRBATI
FEMEI
FIGURA 1. Valoarea medie a indicelui de masă corporală în funcție de prezența sau absența evenimentelor coronariene acute 
FIGURA 2. Prevalența evenimentelor coronariene acute

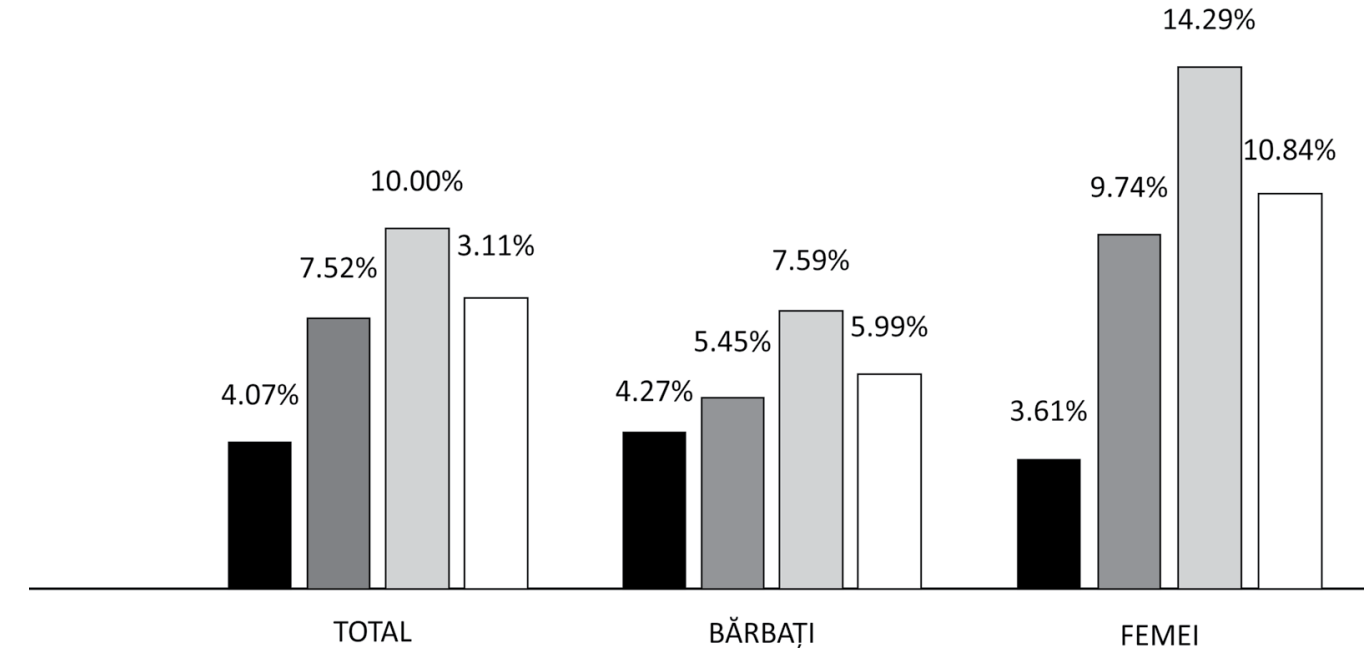

Rezultatele în funcție de gen la bărbați au relevat o prevalență a ECA la normoponderali de $4,27 \%$ și 5,99\% la cei cu IMC > 25, dintre care $5,45 \%$ cei supraponderali și 7,69\% la cei obezi.

La femei, IMC a avut un rol mult mai însemnat în relația cu frecvența evenimentelor coronariene acute. Prevalența ECA a subiecților de gen feminin a fost de 3,61\% pentru cele cu IMC < 25 și 10,84\% pentru cele cu IMC > 25, 9,74\% pentru cele supraponderale și $14,29 \%$ pentru cele obeze.

Infarctul miocardic acut a fost prezent la subiecții normoponderali în procent de 0,9\%, comparativ cu subiecții cu IMC > 25 în procent de $2,15 \%$, cu cei supraponderali de 1,25\% și cei obezi de $5 \%$.

Infarctul miocardic acut la persoanele masculine a avut o prevalență de 1,22\% la normoponderali, $1,84 \%$ la supraponderali și obezi, $1,81 \%$ la supraponderali și 1,96\% la persoanele cu obezitate.

La subiecții feminini, prevalența a fost de 0,36\% la cele normoponderale comparativ cu femeile supraponderale și obeze, unde prevalența IMA a fost de $2,96 \%$, dintre care 1,36 cele supraponderale și $8,16 \%$ cele obeze.

Prevalența anginei instabile la subiecții normoponderali $(3,39)$ a fost de 2 ori mai mică decât prevalența la subiecții cu valori ale IMC peste valorile normale (6,68\%), 6,90\% la supraponderali și 6,00\% la obezi.

\section{REZULTATE ŞI DISCUȚII}

Valoarea medie a IMC la subiecții afectați de ECA $(24,69)$ nu a variat elocvent comparativ cu valoarea medie a IMC a subiecților fără ECA $(25,76)$.

Comparând însă doar valorile medii, nu se poate analiza relația intimă dintre una dintre modalitățile cele mai sensibile de apreciere ale obezității și frecvența ECA, fiind necesară aprecierea dispersiei datelor și, mai ales, comportamentul extremelor, în special al valorilor care încadrează subiecții în categoria obezității; de aceea, se va urmări frecvența ECA la aceste categorii.
FIGURA 3. Prevalența infarctului miocardic acut

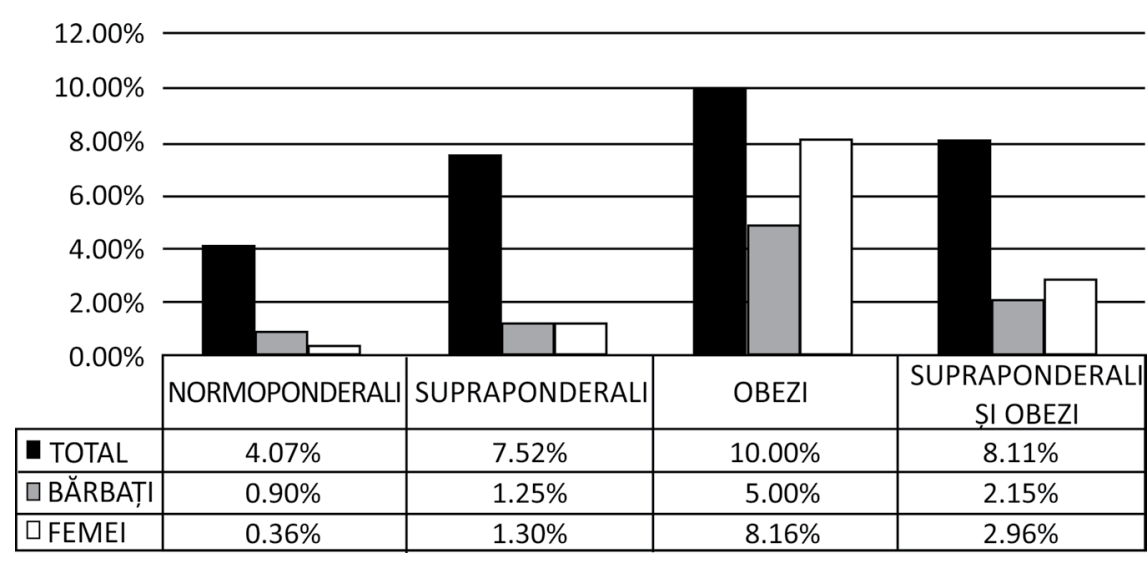




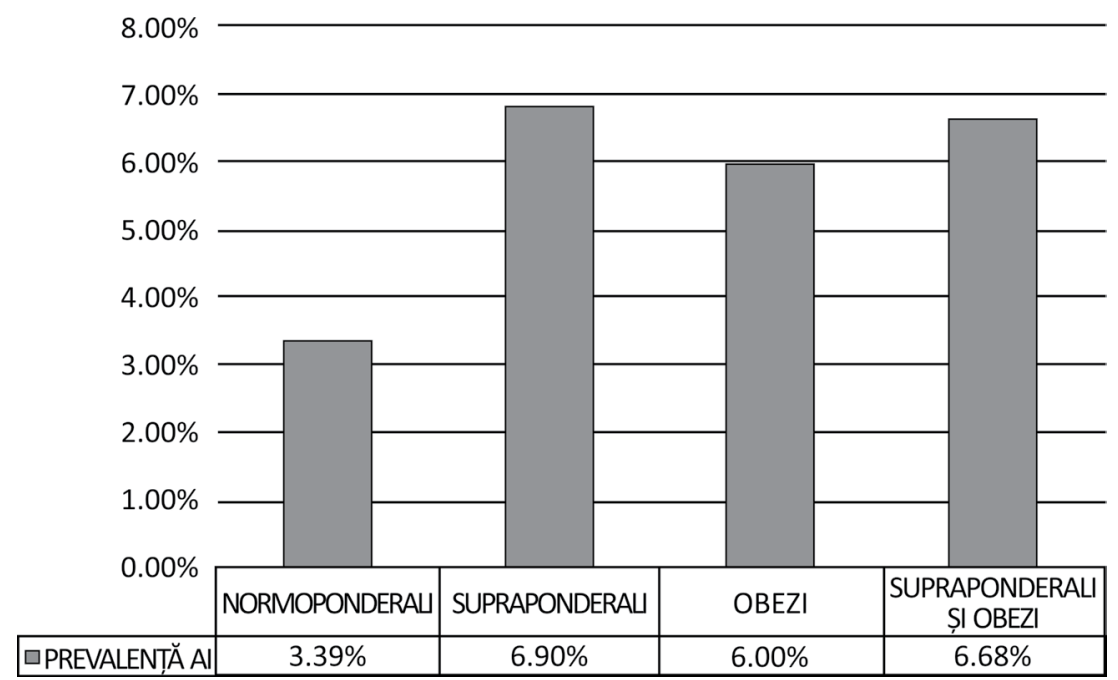

FIGURA 4. Prevalența anginei instabile

Valoarea medie a IMC la cei cu evenimente coronariene acute a fost cu doar $5 \%$ mai mare (media 24,69; IC95\% al mediei 24,381-25,005; DS 4,517; mediana - 24,38; limite 16,63-44,17) față de media indicelui de masă corporală înregistrat la subiecții fără evenimente coronariene acute (media - 25,76; IC95\% al mediei 24,383-27,138; DS 4,95; mediana - limite 16,53-41,27).

Valorile medii ale IMC la subiecții de gen masculin au condus la valori foarte apropiate la subiecții afectați de evenimente coronariene acute (media $=26,64 ;$ DS - 4,1605; IC95\% al mediei 24,694-28,588; limite 21-41,27) și la cei fără evenimente coronariene acute (media $=25,90$; DS 4,23; IC95\% al mediei 25,466-26,340; limite 15,67$44,17)$, diferența mică dintre cele două medii nefiind semnificativă statistic $(p=0,58)$.

La subiecții de gen feminin, s-a observat o diferență semnificativă $(p=0,0463)$ între media valoriIor IMC la cazurile cu ECA (media -25,21; IC95\% al mediei 23,273-27,147; DS - 5,37; mediana -25,675) și media valorilor subiecților fără ECA (media 23,718; IC95\% al mediei 23,298-24,137; DS 4,5149; mediana - 23,04; limite 15,67-42,24).

Prevalența ECA la subiecții cu IMC peste 25 (supraponderali și obezi) a fost aproximativ dubla valorilor indicelui de masă corporală mai mari de 25 , aceasta a fost dublă $(8,11 \%)$ în comparație cu prevalența ECA la subiecți normoponderali, cu un indice de masă corporală sub 25 (4,07\%).

Riscul ECA la subiecții cu IMC peste 25 , subiecții supraponderali sau obezi, a fost de 2,2 ori mai mare comparativ cu cei normoponderali, cu IMC < $25(\mathrm{RR}=2,2 ; \mathrm{IC95} \%$ al RR 1,2651-3,8357; $\mathrm{p}=$ $0,005)$, valoarea riscului relativ având o semnificație statistică înaltă $(p=0,005)$.
Prevalența ECA a prezentat o tendință ascendentă în corelație cu creșterea IMC, valoarea prevalenței evenimentelor coronariene acute fiind maximă la subiecții al căror IMC îi încadra în clasa obezității (10\%) și de 7,52\% la subiecții supraponderali.

Riscul a fost, totodată, mai ridicat la cei cu obezitate comparativ cu subiecții normoponderali, valoarea riscului fiind de 2,5 ori mai mare la obezi, fiind și aici identificată semnificația statistică necesară validării rezultatelor $(\mathrm{RR}=2,45$; IC95\% 1,16935,1567; $p=0,0176$ ).

Prevalență evenimentelor coronariene acute la subiecții supraponderali $(7,52 \%)$ a fost cu peste $50 \%$ mai mare decât la subiecții normoponderali, riscul la subiecții supraponderalii a fost, astfel, de 1,72 ori mai ridicat față de normoponderali $(\mathrm{RR}=$ 1,718; IC95\% 0,948-3,114; $p=0,0744$ ).

Încercarea de a evalua o frecvență mai mare la categoria de subiecți supraponderali alături de cei obezi riscă să nu fie elocventă, prevalența ECA la subiecții supraponderali și obezi fiind de aproape $6 \%$, comparativ cu cea observată la subiecții normoponderali.

Gruparea subiecților obezi de gen masculin, cei cu IMC > 30, a condus la o prevalență $(7,69 \%)$ de aproape 2 ori mai mare față de normoponderali și cu $40 \%$ mai mare față de supraponderali, confirmând aceeași tendință de creștere a prevalenței ECA odată cu creșterea IMC.

Chiar dacă riscul la bărbații cu obezitate a fost de 1,8 ori mai mare față de subiecții normoponderali, pentru cei supraponderali comparația cu cei normoponderali nu a surprins un risc mai mare ale evenimentelor coronariene acute $(R R=1,28$; IC95\% 0,4874-3,3503; $p=0,62$ ), neputând fi asigu- 
rată de către datele studiului semnificația statistică necesară nici pentru riscul cumulat al supraponderalilor și obezilor față de normoponderali $(P=$ 0,4584).

IMC la subiecții feminini a avut un rol mult mai puternic în relația cu frecvența ECA. Femeile cu IMC peste 25 au avut o prevalență de 10,84\%, această valoare fiind de trei ori mai mare decât prevalența ECA de la subiecții de gen feminin normoponderali de 3,61\%, 9,74\% pentru cele supraponderale și 14,29\% pentru cele obeze, fiind de 4 ori mai mare față de cazurile normoponderale.

Riscul ECA la persoanele feminine obeze a fost de 4 ori mai mare comparativ cu cazurile normoponderale de același gen, riscul având o înaltă semnificație statistică (RR=3,96; IC95\% 1,58199,8988; $p=0,003$ ), iar riscul prezenței aECA al cazurilor de gen feminin supraponderale comparativ cu subiecții al căror indice de masă corporală prezenta valori încadrabile în categoria normoponderală a fost de peste 2,5 ori mai mare $(R R=2,6981$; IC95\% 1,2423-5,8595; $P=0,0121$ ).

Riscul cumulat indiferent de amploarea devierii ascendente a indicelui de masă corporală față de valorile normale ale acestuia a fost de 3 ori mai mare (RR= 3; IC95\% 1,4536-6,1998; $P=0,0030)$.

IMA la subiecții cu IMC peste 25 au avut o frecvență de 2,15\%, fiind de peste două ori mai mare decât prevalența IMA la subiecții cu IMC normal, cu o valoare de $0,9 \%$, la subiecții cu obezitate prevalența infarctului miocardic acut a fost de $5 \%$, iar la supraponderali de 1,25\%.

Riscul IMA la cei cu obezitate a fost de aproximativ 10 ori mai mare comparativ cu subiecții normoponderali (RR=9,56; IC95\% 3-30,45; $P=0,0001$ ), nefiind însă identificat un risc semnificativ mai mare și la subiecții supraponderali $(p=0,64)$.

Corelând riscul cumulat la subiecții obezi și normoponderali, s-a putut estima un risc cumulat al subiecților cu valori ale IMC peste25 de 2,4 ori mai mare comparativ cu subiecții normoponderali.

Discrepanța cea mai mare dintre prevalența IMA la subiecții supraponderali sau obezi, de 2,96\%, și valoarea prevalenței la subiecții normoponderali, de 0,36\%, a fost identificată la femei.

Obezitatea reprezintă unul dintre cei mai importanți vectori asociați cu IMA. La femeile cu obezitate, prevalența IMA de $8,16 \%$ a fost de peste 20 de ori mai mare comparativ cu cea de la normoponderali $(0,36 \%)$ și de peste 6 ori mai mare comparativ cu prevalența IMA de la femeile supraponderale.

Riscul IMA a fost de 22,6 ori mai mare la persoanele feminine obeze ( $R R=22,612$; IC95\% 2,581-198,082; $P=0,0049$ ), iar riscul cumulat al IMA la subiecții de același gen cu valori ale IMA peste valorile normale de 8,18 ori mai mare comparativ cu riscul la subiecții normoponderali (RR = 8,19; IC95\% 1,0933-67,4815; $P=0,0407$ ).

Angina instabilă a prezentat valori ale prevalenței la cei cu IMC sub $25(3,39)$ de 2 ori mai mică decât prevalența la subiecții normoponderali $(6,68 \%)$, prevalența la supaponderali fiind de $6 \%$, iar la cazurile cu obezitate de 6,9\%.

\section{CONCLUZII}

Riscul evenimentelor coronariene acute la persoanele cu IMC > 25 la subiecții supraponderali sau obezi a fost de 2,2 ori mai mare comparativ cu persoanele normoponderale, cu un indice de masă corporală sub valoarea de 25 ( $R R=2,2$; IC 95\% al RR 1,2651-3,8357; $p=0,005)$. Prevalenței evenimentelor coronariene acute i s-a identificat o tendință ascendentă în relație cu creșterea valorilor indicelui de masă corporală, valoarea prevalenței evenimentelor coronariene acute fiind maximă la subiecții al căror IMC îi încadra în clasa obezității (10\%) și de 7,52\% la subiecții supraponderali.

Conflict of interest: none declared Financial support: none declared

\section{BIBLIOGRAFIE}

1. Whitlock $G$, Lewington $S$, Sherliker $P$, the Prospective Studies Collaboration. Body-mass index and cause-specific mortality in 900,000 adults: Collaborative analyses of 57 prospective studies. Lancet. 2009;373:1083-1096.

2. Wormser D, Kaptoge S, Di Angelantonio E. The Emerging Risk Factors Collaboration Separate and combined associations of body-mass index and abdominal adiposity with cardiovascular disease: Collaborative analysis of 58 prospective studies. Lancet. 2011;377:1085-1095.

3. Singh GM, Danaei G, Farzadfar F. The Global Burden of Metabolic Risk Factors of Chronic Diseases Collaborating Group. Asia-Pacific Cohort Studies Collaboration (APCSC) the Diabetes Epidemiology: Collaborative analysis of Diagnostic criteria in Europe (DECODE) the Emerging Risk
Factor Collaboration (ERFC) the Prospective Studies Collaboration (PSC) The age-specific quantitative effects of metabolic risk factors on cardiovascular diseases and diabetes: A pooled analysis. PLoS One. 2013;8:e65174.

4. Franz MJ, VanWormer JJ, Crain AL. Weight-loss outcomes: A systematic review and meta-analysis of weight-loss clinical trials with a minimum 1-year follow-up. J Am Diet Assoc. 2007;107:1755-1767. 
5. Douketis JD, Macie C, Thabane L, Williamson DF. Systematic review of long-term weight loss studies in obese adults: Clinical significance and applicability to clinical practice. Int $J$ Obes (Lond) 2005;29:1153-1167.

6. Gray LJ, Cooper N, Dunkley A. A systematic review and mixed treatment comparison of pharmacological interventions for the treatment of obesity. Obes Rev. 2012;13:483-498.

7. Rucker D, Padwal R, Li SK, Curioni C, Lau DC. Long term pharmacotherapy for obesity and overweight: Updated meta-analysis. BMJ. 2007;335:1194-1199.

8. Sjöström L, Narbro K, Sjöström CD. The Swedish Obese Subjects Study Effects of bariatric surgery on mortality in Swedish obese subjects. N Engl J Med. 2007;357:741-752.

9. Buchwald $\mathrm{H}$, Avidor $\mathrm{Y}$, Braunwald $\mathrm{E}$. Bariatric surgery: A systematic review and meta-analysis. JAMA. 2004;292:17241737.

10. Eknoyan G. Adolphe Quetelet (1796-1874) - the average man and indices of obesity.
Nephrol Dial Transplant. 2008 Jan;23(1):4751. .

11. Blackburn H, Jacobs D. Commentary: Origins and evolution of body mass index (BMI): Continuing saga. Int J Epidemiol. 2014 Jun;43(3):665-9.

12. Jeremy Singer-Vine. Beyond BMl: Why doctors won't stop using an outdated measure for obesity. Slate.com. July 20 , 2009.

13. Keys A, Fidanza F, Karvonen MJ, Kimura $\mathrm{N}$, Taylor HL. Indices of relative weight and obesity. Int J Epidemiol. 2014 Jun;43(3):655-65.

14. Coteanu I, Seche L. Dicţionarul explicativ al limbii române, ed. a II-a, Ed. Univers Enciclopedic, Bucureşti, 1998.

15. Haslam DW, JamesWP. Obesity. Lancet. 2005 Oct 1;366(9492):1197-209.

16. http://www.medicalnewstoday.com/ releases/24118.php.

17. Poulain M, Doucet M, Major GC et al. The effect of obesity on chronic respiratory diseases: Pathophysiology and therapeutic strategies. CMAJ. $2006 \mathrm{Apr}$ 25;174(9):1293-9.
18. Finucane MM, Stevens GA, Cowan MJ, for the Global Burden of Metabolic Risk Factors of Chronic Diseases Collaborating Group (Body Mass Index). National, regional, and global trends in body-mass index since 1980: Systematic analysis of health examination surveys and epidemiological studies with 960 countryyears and 9.1 million participants. Lancet. 2011 Feb 12;377(9765):557-67.

19. Caballero B. The global epidemic of obesity: An overview. Epidemiol Rev. 2007;29:1-5.

20. Haslam D. Obesity: A medical history. Obes Rev. 2007 Mar;8 Suppl 1:31-6.

21. World Health Organization. Obesity and overweight. Accesat în 8 aprilie 2009.

22. Tsigos C, Hainer V, Basdevant A, Finer N, Fried M, Mathus-Vliegen E, Micic D, Maislos M, Roman G, Schutz Y, Toplak H, Zahorska-Markiewicz B; Obesity Management Task Force of the European Association for the Study of Obesity. Management of obesity in adults: European clinical practice guidelines. Obes Facts. 2008;1(2):106-16. 